\title{
CASA-EXÍLIO', PALAVRA-MAPA
}

Home-exile, map-word

Casa-exilio, palabra-mapa

> Karina Dias [Universidade de Brasília, Brasil]*

Luciana Ferreira [Universidade de Brasília, Brasil) * *

\begin{abstract}
RESUMO O que é o exílio? - esta é a questão que norteia o diálogo entre dois pensamentos. No primeiro, o exílio é entendido como a perda de uma casa, um lançamento no mundo, onde a procura da casa acontece de forma incessante e sem garantias. No segundo, o exílio é vivido como a perda do mundo pela condição de se ter que permanecer dentro da própria casa, portanto, quando o mundo precisa ser percorrido e inventado entre as suas paredes. $O$ texto explora as nuances desses dois pensamentos em diálogo com trabalhos de artistas visuais e, em alguns momentos, na sua relação com a palavra, ora uma palavra exilada, ora uma palavra-mapa.

PALAVRAS-CHAVE Casa; exílio; palavra; arte contemporânea.
\end{abstract}

* Karina Dias é Pesquisadora e Professora associada do Departamento de Artes Visuais da Universidade de Brasília. E-mail: karinadias. net@gmail.com

* * Luciana Ferreira é Pesquisadora no Programa de Pós-graduação em Artes Visuais (PPGAV) da Universidade de Brasília. E-mail: lusmferreira@yahoo.com.br 
DIAS, Karina; FERREIRA, Luciana. Casa-exílio, palavra-mapa. Revista Poiésis, Niterói, v. 23 , n. 39, p. 205 223, jan./jun. 2022 [DOl: https://doi. org/10.22409/poiesis.v23i39.48997]

Este documento é distribuído nos termos da licença Creative Commons AtribuiçãoNão Comercial 4.0 Internacional (CCBY-NC) (c) 20221 Karina Dias, Luciana Ferreira. Submetido: 5/3/2021; Aceito: $25 / 5 / 2021$
ABSTRACT What is the exile? - that is the question that guides the dialogue between two thoughts. In the first one, the exile is understood as the loss of a home, a launch to the world, where the search for a home happens in an incessant and free of guarantee way. In the second one, the exile is experienced as the loss of the world for the condition of having to remain inside its own house, therefore, when the world needs to be crossed and invented between its walls. The text explores the nuances of these two thoughts in dialogue with the works of visual artists and, at some points, in its relationship with the word, sometimes an exiled word, sometimes a map-word.

KEYWORDS Home; exile; word; contemporary art.

RESUMEN ¿QQué es el exilio? - esta es la cuestión que guía el diálogo entre dos pensamientos. En el primer, el exilio es entendido como la pérdida de una casa, un lanzamiento al mundo, en donde la búsqueda de la casa ocurre de forma incesante y sin garantías. En el segundo, el exilio es vivido como la pérdida del mundo por la condición de tener que permanecer dentro de la propia casa, por lo tanto, cuando el mundo necesita ser recorrido e inventado entre sus paredes. El texto explora los matices de esos dos pensamientos en diálogo con trabajos de artistas visuales y, en algunos momentos, en su relación con la palabra, por veces una palabra exiliada, por veces una palabra-mapa.

PALABRAS CLAVE Casa; exílio; palabra; arte contemporâneo. 
Ana Maria Martins, em Como se fosse a casa[2017], escreve:

a vontade de partir antecede sempre

a casa

estamos para ir

prestes, mas não prontos

só vigor e vontade

lar, ela pensa, é sempre lá

Talvez assim comece o exílio. Sem dúvida, é a procura de uma casa. Acontece quando a casa que temos, por desejo ou por necessidade, não pode mais permanecer. É preciso partir.

Em outra passagem do mesmo texto [2017], Ana Maria Martins continua: espaço interior, elegeu a casa como elemento privilegiado. Seria ela o "nosso canto do mundo", o nosso "primeiro universo", um lugar de acolhimento dos nossos sonhos e devaneios. Sonhos e devaneios exigiriam a segurança de paredes sólidas e de um teto que protegeria das tempestades, um "não-eu que protege o eu" [BACHELARD, 2008, p.24]:

[...] todo espaço realmente habitado traz a essência da noção de casa.

[...] Na vida do homem, a casa afasta contingências, multiplica seus conselhos de continuidade. Sem ela, o homem seria um ser disperso. [BACHELARD, 2008, p.24-26]

A casa teria, assim, um valor intrinsecamente maternal, de profundo amparo, proteção e acolhimento da existência humana. E haveria, como referência mais profunda, a "casa natal", a casa das memórias mais antigas, onde os hábitos se firmaram:

penso que só sabe da casa quem precisa atravessar rapidamente uma fronteira quem fez sua casa num país que não o quer aqueles a quem a casa segue como um cão

Bachelard, pretendendo fazer uma fenomenologia do espaço e, com ela, dos valores de intimidade do
A casa natal é a casa habitada [...] para além das lembranças, a casa natal está fisicamente inserida em nós. Ela é um grupo de hábitos orgânicos. [...] gravou em nós a hierarquia das diversas funções de habitar. Somos o diagrama das funções de habitar aquela casa; e todas as outras não passam de variações de um tema fundamental. [BACHELARD, 2008, p.33-34] 
existência com o lugar. Estabelece padrões que sugerem a estabilidade e permitem que a casa habitada cumpra a sua função de proteção. O hábito adquirido no habitar a casa natal é transferido para e reproduzido nas outras casas, perpetuando a sensação de segurança.

Mas acontece de perder a casa. Acontece o exílio. Como segue esse que perdeu o seu canto do mundo? Para onde vai esse ser agora disperso?
Estas questões nos tomam com sua máxima intensidade quando nos deparamos com as imagens de Centro di permanenza temporânea. Um vídeo registra pessoas - claramente imigrantes - em uma escada de aeronave, em uma pista de um aeroporto, sem qualquer avião próximo. Não sabemos de qual aeroporto se trata, não sabemos a que país pertence, não sabemos quem são essas pessoas, não sabemos de onde vieram, não sabemos para

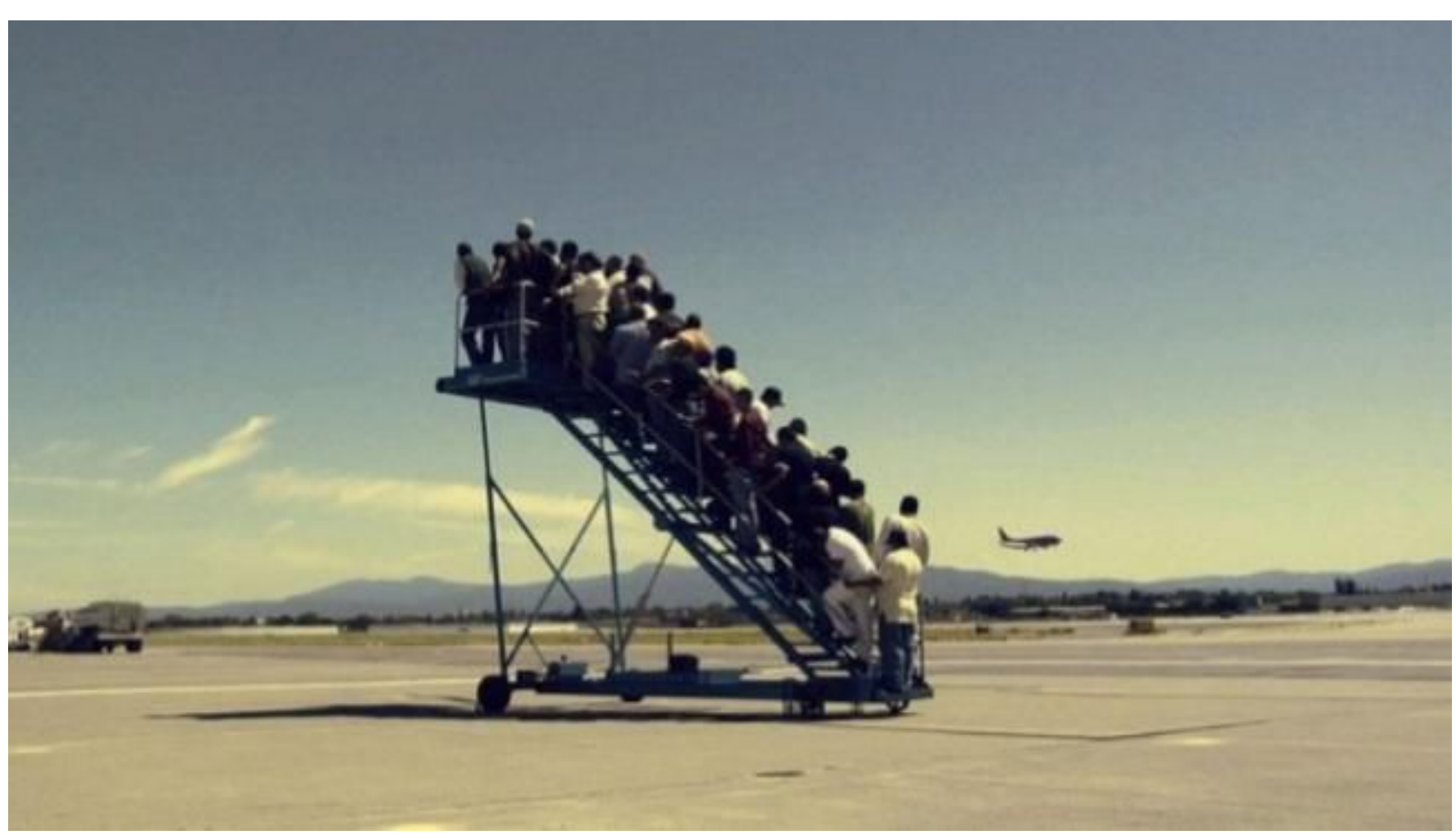

Fig. 1 - Adrian Paci, Centro di permanenza temporanea, 2007

Fonte: https://welldesignedandbuilt.com/2012/03/02/adrian-paci-centro-di-permanenza-temporanea/[acesso em 18.02.21]

DIAS, Karina; FERREIRA, Luciana. Casa-exílio, palavra-mapa. 
onde vão. Não possuem sequer bagagem. Apenas esperam em um espaço suspenso que é também um hiato temporal entre o que foi e o que será. A imagem, que por vezes enquadra alguns rostos, não nos informa nada. Dá-nos apenas o duro contato com a espera calma, desinformada, lacunar de pessoas que não conseguem pisar o chão, deslocadas no próprio lugar. ${ }^{2}$

O expatriado é para Blanchot não apenas aquele que perdeu seu país, mas o que descobriu um modo de habitar sem hábito [BLANCHOT, 2010b, p.42]. O exílio que enfrenta exige o abandono do hábito. Por isso a casa é difícil, embora permaneça sempre uma procura incessante. Uma procura, por força, desapegada da casa natal. Uma procura, porquanto urgente, não exigente. O exílio é um trânsito, uma chegada que não se conclui, uma partida que nunca termina. Um estado suspenso. Todo exilado é um estrangeiro diante do mundo e diante de si mesmo.

Mas, quem é o estrangeiro? - pergunta Maldonado. E ensaia uma resposta:

[Aquele que] Vem de longe. [...] [que] tem que deixar a terra dos pais, a casa, a memória. [...] Migra, o estrangeiro. E ao migrar desmancha qualquer vínculo com a saudade e a tradição [...] Seus adeuses não deixam rastro ou memória. Nenhuma memória tem respostas. Pois nenhuma resposta pode se dar senão o olvido: o olvido que se torna ausência; a ausência que para dizer de si não necessita raízes; raízes que o êxodo da língua materna e da ilusão de que uma palavra possa des-velar [e não apenas revelar] transforma em pura errância. [MALDONADO, 2004, p. 30-31]
O estrangeiro é o que se despede. Deixa para trás a estabilidade da casa e dos sonhos. Deixa para trás a língua materna, a casa de todas as casas. Salta em um abismo de profundidade não mensurável, onde não se faz abrigo. O estrangeiro é uma pergunta. E, sendo essa pergunta inquieta e insistente, ela mesma imprecisa, já não espera por qualquer resposta.

Um estrangeiro nunca se sente em casa. Ele atravessa a soleira de uma casa que não lhe pertence e espera, nela, encontrar hospitalidade. "A hospitalidade pressupõe [...]a possibilidade de uma delimitação rigorosa das soleiras ou fronteiras: entre o familiar e o não-familiar, entre o estrangeiro e o não-estrangeiro" [DERRIDA, 2003, p.43]. E, uma vez atravessada a soleira, aquele diante do estrangeiro, primeiramente, pergunta-Ihe o nome. Não se oferece hospitalidade sem que o estrangeiro se defina como estrangeiro. É preciso saber quem ele é e de onde vem para submetê-lo às leis da hospitalidade, pois, "do ponto de vista do direito, o hóspede, mesmo quando bem recebido, é antes de tudo um estrangeiro, ele deve continuar estrangeiro." [DERRIDA, 2003, p.63]. E tudo isso já está posto no momento primeiro quando, atravessada a soleira, o estrangeiro precisa se apresentar em uma língua que não Ihe pertence. 
Mas Derrida se pergunta se não seria possível outra hospitalidade:

A hospitalidade consiste em interrogar quem chega? Ela começa com a questão endereçada a quem vem [...]: como te chamas? [...] Ou será que a hospitalidade começa pela acolhida inquestionável, num duplo apagamento, o apagamento da questão e do nome? É mais justo e mais amável perguntar ou não perguntar? [...] Oferece-se hospitalidade a um sujeito? A um sujeito identificável? A um sujeito identificável pelo nome? Um sujeito de direito? Ou a hospitalidade se torna, se dá ao outro antes que ele se identifique, antes mesmo que ele seja [posto ou suposto como tal] sujeito, sujeito de direito e sujeito nominável por seu nome de família, etc? [DERRIDA, 2003, p.26-27] venda a sua imagem de "homem exótico". A placa é escrita em inglês, língua oficial do país onde se encontra, diante do qual, enquanto homem exótico, afirma-se como o estrangeiro deslocado, não pertencente. Ao colocar a sua imagem à venda, negocia a sua permanência. A cena acontece, entre outros momentos, diante de uma kombi repleta de bananas, dentro da sua exposição na Art Basel, em Miami. Aqui, o estrangeiro parece submeter-se, com ironia, às leis da hospitalidade impostas pelo direito local.

Há, na hospitalidade, uma antinomia entre as leis da hospitalidade previstas pelo direito e a lei incondicional da hospitalidade. São dois regimes contraditórios e inseparáveis, onde a lei incondicional necessita das leis do direito enquanto as corrompe e subverte, pois a lei incondicional da hospitalidade seria sem lei, desprovida de deveres e imperativos [DERRIDA, 2003, p.69-73].

Esgarçar ao limite a questão do estrangeiro e da hospitalidade foi o que fez Paulo Nazareth. Em 2011, percorreu a pé e de carona o caminho da sua casa em Minas Gerais até a América do Norte. No percurso, fez uma série de registros da experiência que estão reunidos no trabalho Notícias da América. Em um desses registros, o artista carrega no peito uma placa de papelão escrita à mão onde coloca à
Em outro momento desse percurso, Paulo Nazareth está em frente a uma placa do estado do Arizona onde, dessa vez, carrega no peito outra placa de papelão escrita à mão, agora em espanhol, dizendo que também temos direito àquela paisagem. Então, Nazareth afirma a América Latina reivindicando o pertencimento ao lugar. Neste momento, há uma tentativa de explosão de fronteiras:

Mi concepto de patria todos los dias se expande... nascido en Brasil soy latino americano, siendo latino americano soy tambien mexicano... soy parte de cada tierra por donde pisaron mis pies... no hay como separar estas tierras con una linea imaginaria llamada frontera... quiza sea por eso que llevantaron el muro al norte: un intento de impedir que Mexico siga siendo Mexico adentro de Estados Unidos. [NAZARETH, 2009, s/p] 


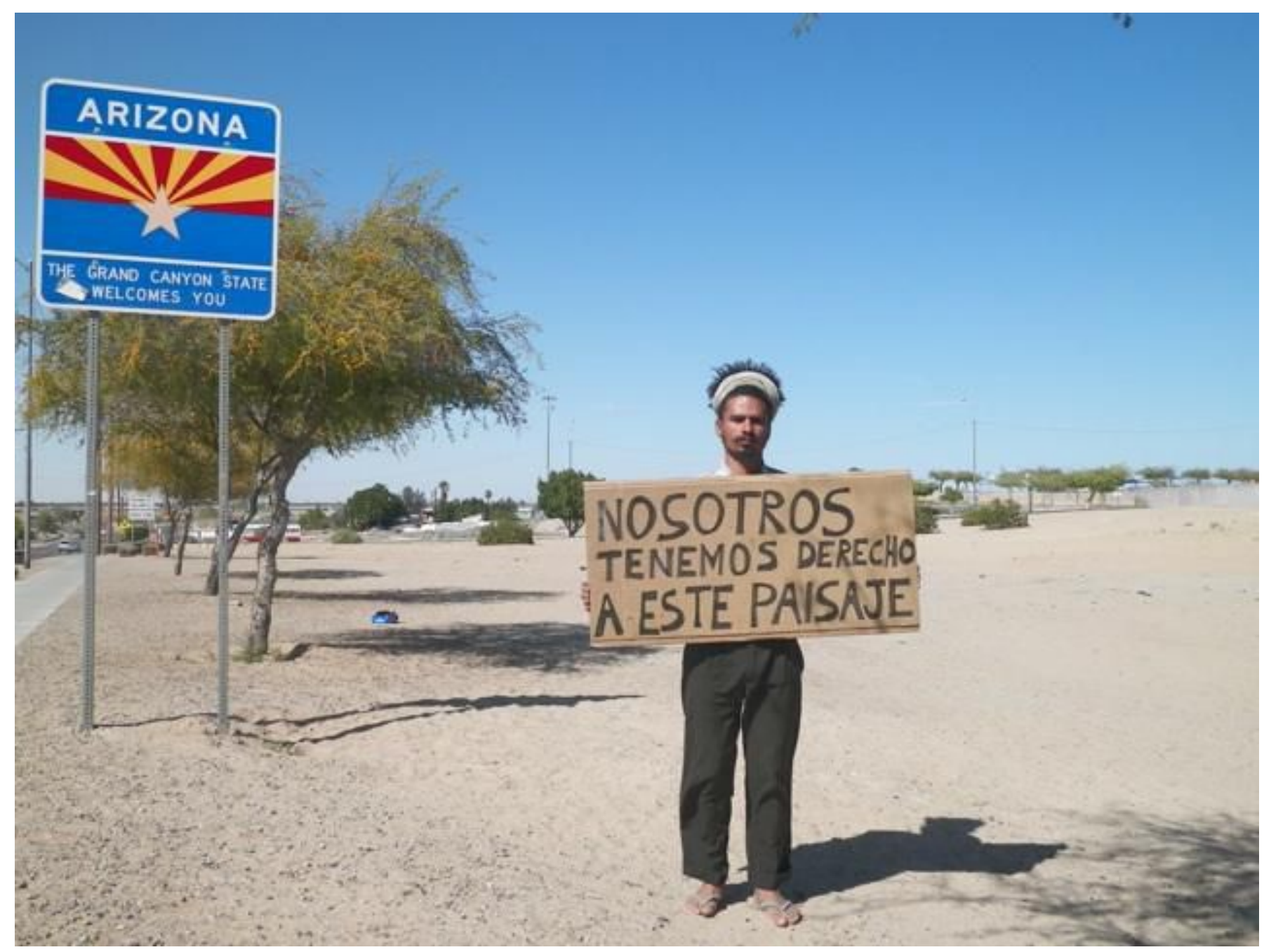

Fig.3 - Paulo Nazareth, série Notícias da América, 2011 -2012

Fonte: https://artebrasileirautfpr.wordpress.com/2013/02/26/paulo-nazareth/[acesso em 18.02.21] 
Outro estrangeiro, Edmond Jabès, de uma família de origem judia francófona, nascido no Cairo, com nacionalidade italiana [sem jamais ter vivido na Itália], exilou-se na França. Em certo momento, afirmou nunca saber onde se encontrava, pois se sentia na França quando habitava o Egito e, uma vez na França, sentia-se sempre em outro lugar. "O estrangeiro já não sabe qual é o lugar" [Jabès, in MALDONADO, 2004, p.29]. E assim seguiu, ainda que desejando firmar morada, sem apego a ela, fazendo da sua existência uma contínua viagem onde tudo é transitório.

Disse Jabés:

$[\ldots]$

Deixei uma terra que não era minha,

troquei-a por outra que, tampouco, me pertence.

Refugiei-me num vocábulo de tinta, que tem o livro como espaço;

palavra de lugar nenhum, palavra obscura do deserto.

Não me cobri, à noite.

Não me protegi do sol.

Andei nu.

De onde eu vinha, já não tinha sentido.

Para onde ia, não havia quem se importasse.

Vento, digo-lhes, vento.

E um pouco de areia no vento.

[JABÈS in MALDONADO, 2004, p.29]
E segue Jabès compartilhando o sentido do deserto imagem escolhida por ele para traduzir a sua errância exilada - a partir da experiência de quem o viveu na carne como ferida exposta. O deserto é, para ele, ausência de paisagem, o lugar de um não-lugar, ausência de qualquer referência e, portanto, ao mesmo tempo, distância e não distância, e ainda a própria separação que é abertura do lugar [JABÈS, 1991, p.61]. Assim como é o deserto, é também o exílio.

Ora, se há deserto [se há exílio], se não há casa, há de se buscá-la. Ainda que sem hábito, habitar. De alguma maneira, encontrar uma forma de estar em um lugar. Uma forma de "organizar, entretanto, esta terra como residência." [BLANCHOT, 2010a, p.73] Jabès confessa ter encontrado abrigo no livro, onde o exílio, de alguma maneira, pôde ser casa.

Curioso que, no máximo da indigência e do não pertencimento, tenha havido esse encontro de um abrigo em um livro, ainda que com "palavras de lugar nenhum". Um refúgio "num vocábulo de tinta, que tem o livro como espaço". Fazer não de um país, mas da língua a casa-exílio. Habitar o estrangeiro na palavra. Pela língua, morar no exterior [não somente de um lugar, mas da experiência]. E, assim, fazer da casa uma intimidade ao avesso, que lança para fora e acolhe no fora. O externo como experiência de morada. A errância como norte e caminho conhecido. A intimidade do fora. 


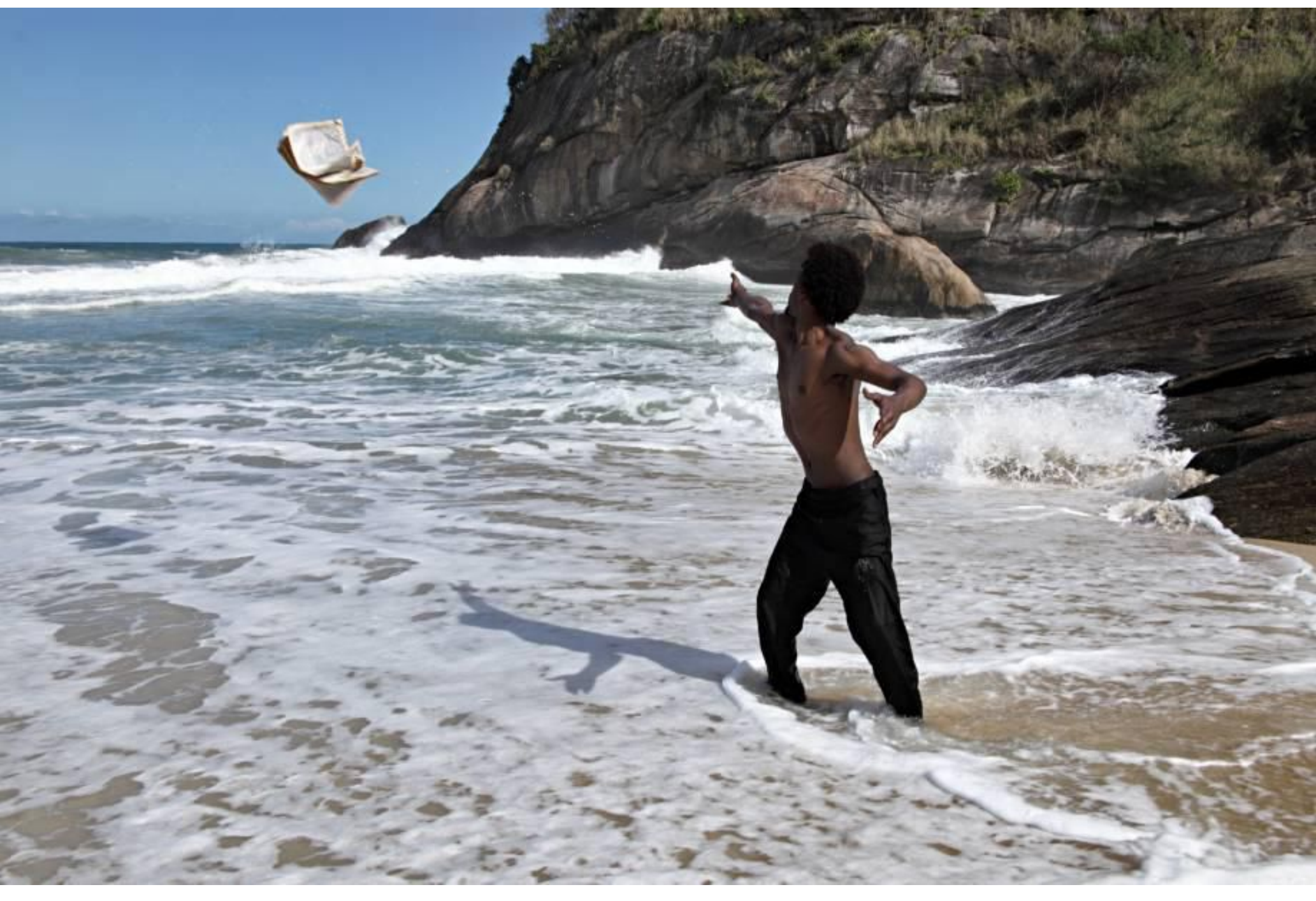

Fig.4: Regina de Paula, Para o levante, 2015-2016

Fonte: : hitps://ogimg.infoglobo.com.br/in/18936623-464-ee0/FT 1086A/652/2016-896524535-para-o-levante_video-regina-de-paula_fotowilton-montenegr.jpg [acesso em 18.02.21]

DIAS, Karina; FERREIRA, Luciana. Casa-exílio, palavra-mapa. 
Blanchot [2010a] fala da "paixão pelo Exterior"3. Para ele, esse é o caminho para se pensar uma língua impossível, ou seja, uma língua que não pode, uma língua sem poder, distante da compreensão apropriadora. Somente uma separação assim infinita, que remete ao absolutamente outro de mim, pode afirmar uma palavra plural, não submetida à violência da única palavra.

A língua que interessa a Blanchot é a língua exilada, a língua que não estabelece morada senão no próprio exílio. A língua interrompida tantas vezes, tão deslocada de si, tão em trânsito, tão estrangeira, que não possa ser tomada como última palavra. Que acolha, portanto, a indigência, a diferença, a dúvida. Uma língua, enfim, sem qualquer verdade, um livro lançando ao mar, como em Para o levante, de Regina de Paula.

Mas, e quando o exterior não é só um lugar infinitamente distante para onde a palavra aponta, mas um lugar dentro da própria palavra? Ou seja, quando, na palavra, o fora se abre por dentro? Nessa língua mal-dita ${ }^{4}$, acontece de o exterior ser íntimo, de o fora ser um tipo de infiltração que toma a palavra na sua intimidade secreta e abala a sua estrutura interna. $\bigcirc$ exterior mergulha na palavra e a divide infinitamente a partir do seu interior. $\bigcirc$ exte- rior, agora, está dentro da palavra, a palavra passa a ser o seu fora. A palavra é exilada de si.

Quando isso acontece, quando a separação infinita está dentro da palavra, a descontinuidade penetra no interstício, no espaço vacante, e segue espaçando ainda mais para que o fora nasça dentro da palavra e the pertença como elemento constituinte fundamental. Enquanto há a intimidade do fora, compreendemos que o fora é também o que há de mais íntimo. 0 infinitamente distante é também o mais próximo.

Essa é a experiência sugerida por Quase notas para quase pensamentos. Nela, um poema de Gertrude Stein e a sua tradução por Augusto de Campos são rasurados com fita corretiva branca, de modo que apenas a última letra antes de cada pontuação e a pontuação correspondente permanecem intactas. Surge, dessa experiência, uma leitura completamente nova. Há, neste trabalho, um convite para uma oralidade primeira, um balbucio de letras soltas, constituído de puro gozo sonoro. Deparamo-nos com uma espécie de coleção de sopros que formam um pequeno texto de quase anotações aéreas às quais correspondem, talvez, pensamentos insipientes, não desenvolvidos, expressos por desenhos visuais desses fragmentos de sons agora estrangeiros no próprio poema de origem. O novo texto deslocado busca abrigo na antiga página-casa que agora se tornou exílio. Pode, a própria casa, ser exílio? 


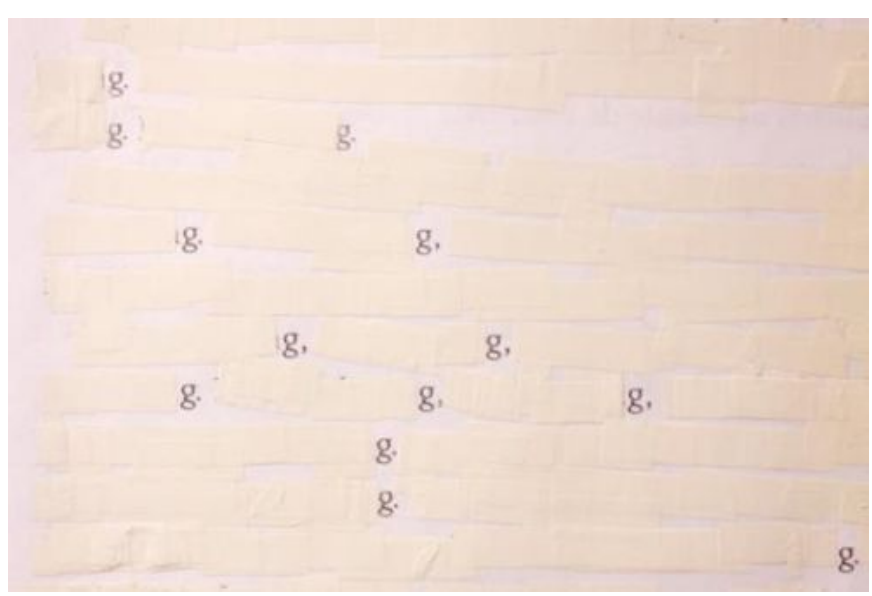

Fig.5 - Luciana Ferreira, Quase notas para quase pensamentos [original e tradução], [detalhes], 2016 Fonte: acervo da artista

\section{CASA-MUNDO OU QUANDO A TERRA NOS EXILA}

Todos os dias vou a minha biblioteca e encontro a coragem, todos os dias abro aleatoriamente um livro, todos os dias leio as mesmas palavras: "onde poderia cair sem desastre?"5

Estar em casa todos os dias até que nos sintamos exilados do mundo. Exilados do mundo, abandonados pela terra 6 . Como nomear aquele que perdeu o mundo? O que permanece como questão? Se um estrangeiro nunca se sente em casa, porque perdeu o teto protetor, em que medida aquele que o.

a.

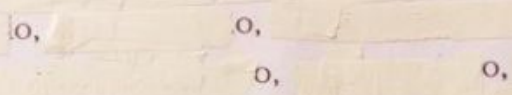

a.

a.

a.

ia.

não pode mais sair de casa se torna também estrangeiro ao teto que o protege? A quem esperamos dar hospitalidade quando aquele que chega somos nós mesmos? Já não sabemos qual o nosso lugar. Permanece, como nos lembra Anne Dufourmantelle [2003, p.50] o onde, como sendo a questão do homem. A autora continua salientando que Derrida nos faz compreender que ao próximo não se opõe o algures, mas uma outra figura do próximo. E esta geografia nos conduz ao onde? Nos conduz a interrogar-nos sobre a relação essencial com o lugar, com a morada e com o sem-lugar. Na impossibilidade de estarmos no mundo atravessamos a soleira de nossas casas para aí permanecermos indefinidamente. $\bigcirc$ que era antes um território está- 
vel, agora se transforma em um espaço em que as fronteiras entre o interior e o exterior se encontram esfumaçadas. Se a hospitalidade é uma relação ambivalente com o espaço e se revela como um gesto de acolhida, de dar lugar a quem chega [DUFOURMANTELLE, 2003, p.58], sejamos nós aqueles que, a um só tempo, acolhem incondicionalmente a própria casa e são acolhidos por ela. Casa [in] cômoda, que nos confirma que não ocupamos mais o centro da cena, que perdermos o ponto de vista privilegiado sobre as coisas e nos sentimos à beira do abismo. Deslocados não reinamos mais despotamente. Fomos lançados à margem para, dali quem sabe, reinventar uma existência.

Nesse movimento, a casa-forte que nos protege da eminente ameaça é também o farol ${ }^{7}$ por onde observamos os movimentos da terra. Se habitar é uma geografia [DELEUZE, PARNET, 1996, 159] é preciso reencontrar o seu relevo. Nesse estado-de-cabana permanecemos [i]móveis?

Levinas nos lembra que ao nos deitarmos, ao nos encolhermos em um canto para dormir, nos abandonamos ao lugar, ele se torna nosso refúgio como base [LEVINAS, 1993, p.119]. O geógrafo Eric Dardel [DARDEL, 2011, p.41] completa que é desse lugar, base de nossa existência que despertando, tomamos consciência do mundo e saímos ao seu encon- tro. Na impossibilidade de sairmos audaciosamente rumo aos espaços para além da casa, nos resta compreender que a casa é um vasto mundo. Não há como não lembrar de Mercator[1609], cartógrafo flamengo do século XVI, que descrevia a casa como um pequeno mundo e o mundo como uma grande casa. Mas a pergunta que nos assombra atualmente e que se mantém como um sussurro incessante é o que acontece quando perdemos o mundo? Vale reler o poema de Albert Camus [1939-53] Do mar bem perto onde o poeta escreve:
... quando perdi o mar, todos os luxos passaram a ter para mim aparência opaca .... Desde então espero. Espero as naves de retorno, a morada das águas, o dia límpido. Aguardo pacientemente com todas as minhas forças muito bem brunidas. [CAMUS, 1939-53]
Perder o mar, perder a paisagem, como se todas as paisagens tivessem, momentaneamente, recuado e nesse recuo, resta-nos ocupar uma exígua faixa de terra [MALDONADO, 2004], um solo primeiro que nos convida a experimentar de forma radical a nossa casa. Confinados em nossas moradas, experimentamos distâncias que nos conduzam ao que nos resta da concretude do mundo [a sua materialidade] e a uma topologia mental, uma finisterra do espírito como afirma Kenneth White [WHITE,1987]. Nessa dinâmica toda imagem fabrica distâncias, cria tempos distintos, é ponto de vista e ponto de 
contato, detalhe e panorama. Nesse desejo de espaço, espaçamo-nos... somos um corpo movendo-se no espaço [WHITE,1994] criamos paisagem, inventamos lugares, deambulamos, talvez, em busca de um alhures possível... lá, onde estivermos.

Emergiriam daí outras rotas, um espaço de navegação a bordo de todos os dias ${ }^{8}$ ? Vagamos, quem sabe, em busca dos ventos, dos mares e das correntezas, franqueamos distâncias, entrevemos continentes. Companheiros de um lugar que só conhecíamos, muitas vezes, de passagem, somos nesse exílio forçado viajantes das pequenas distancias. Habitar a proximidade como se um longínquo fosse, compreender que o espaço é sempre uma dúvida9 ${ }^{9}$ que a realidade geográfica é, como escreve Dardel [DARDEL, 2011], o lugar onde estamos. Nessa morada do íntimo, como [não] pensar em paisagem? Se a paisagem é a medida do olhar que silencia o ruído, ela também é onde a terra e o céu se tocam [CORAJOUD apud ROGER, 1995], um movimento mínimo e uma revolução máxima, sempre entre visão e invisão [DIAS, 2010] essa ressonância interna que nos confirma que a paisagem é mais que um simples ponto de vista óptico. Nessa justa aliança que une o lado objetivo daquilo que vemos com o lado subjetivo, íntimo a cada um de nós, a paisagem é um como-ver-se. Um ver de dentro que se desdobra no fora. Estar incluído e saber-se dis- tância. Nesse movimento nem sempre dócil, o olho que olha é também o que sonha.

Nesse exílio-morada-exílio, pode a paisagem morar na palavra? Pode a palavra armazenar o horizonte, condensar o mundo, sustentar a sua arquitetura? Habitar todas as línguas, escutar uma língua muda, praticar uma língua nômade, encontrar as palavras corajosas. [GALLIENNE, 2020], indagar os nomes. Reencontrar o caminho de volta à terra, sem esquecer que "bastaria um movimento de distração para afogar os cinco continentes. O mar não tem remorso..." [JABÈS apud MALDONADO, 2004, s/p] Pelas palavras chegar, pelas palavras refundar a morada

\section{A PALAVRA-MAPA:}

"Vocês, palavras, levantem, sigam-me e quando tivermos ido longe demais, iremos ainda mais longe, isso não tem fim", escreve a poeta Ingeborg Bachmann [BACHMANN, 2020, p.127]. O que resta quando a linguagem silencia? O vento, a respiração, a distância entre os corpos que se movem, as palavras miúdas ditas pelo caminho, inaudíveis porque, em movimento, são como os invisíveis detalhes que compõe um percurso. Como as flores que ficam na beira da estrada sem nome ou prestígio e que nos lembram que o próximo pode ser 
um vasto mundo. Reencontrar a língua do espaço. Formular efêmeros enunciados. Lem-

brar que mover exige coragem.

Das coisas às palavras, sempre em movimento, sempre movediças. "Como os nomes suportam portar os anônimos, indaga novamente a poeta?" [BACHMANN, 2020 p.25]. Os nomes são geografias, são como vozes que sussurram em uma língua desconhecida. São relevos, apontam direções,

distâncias, topografias nômades.

É preciso reencontrar o mapa. Rever percursos, reler palavras esquecidas, pousar e repousar nas distâncias percorridas, sem sair do lugar. Foi dessa experiência que surgiu o vídeo Sudamérica ${ }^{10}$. Nele o espectador acompanha o deslocamento em um mapa ao mesmo tempo em que uma voz em off narra sobre a viagem, o encontro com as fronteiras, a impossibilidade de se chegar e o que significa partir. No mapa, uma odisseia da palavra.

Se todo mapa é uma sombreada paisagem, é também uma nota, um esboço, uma mirada. Uma mirada forasteira. Uma vista intrusa ao nome. Possibili- dade de medida e efêmero contorno. Uma página para um atlas. O projeto para um globo. Quantos são os percursos, as horas vividas, os dias habitados, as luzes meridianas, o que não está posto?

A terra não cabe num mapa, tampouco as palavras não ditas e a história abandonada como um mato selvagem que encobre toda paisagem esquecida. O que dizem as vizinhanças silenciosas aos ruídos que vem do sul? De terra em terra, percorrer os lugares como se intrusos não fôssemos, nessa impossibilidade permanente, somos estrangeiros aos espaços e a seus nomes, mesmo os mais fraternais. Nessa casa que se tornou mundo, há muitos nomes para os ventos, há muitos 
nomes para os lugares. O movimento foi sempre o mesmo, atravessar de nome em nome uma faixa de terra, estar à margem, entrever um continente imaginado. Com o mapa, dar a volta ao mundo sem sair do lugar, cartografar distâncias oceânicas, fronteiras longínquas e estranhos nomes. As palavras são quilômetros.

Nesse mundo da proximidade que recua, do longínquo que [se] aproxima num instante [MARQUES,2009, p.64], noturnas são as distâncias. Habitar as fronteiras, seus modos, suas línguas, as palavras ferozes, os estranhos nomes. Quantas são as rotas de fuga? Possuir as direções. Guardar as distâncias. Abandonar o mapa, "lá onde a terra é aquilo que podemos perder num instante". [DARDEL, 2011, p.36]

\section{CONCLUSÃO}

O que acontece quando perdemos a casa? O que acontece quando perdemos o mundo? Nestas perguntas, que provocaram a nossa reflexão, duas experiências de exílio distintas se encontram: o exílio fora de casa e o exílio dentro de casa. Como se a casa fosse o lugar onde se quer estar quando é preciso partir, ou o lugar de onde se quer partir, quando é preciso estar. Em meio a tudo isso, surge a relação do exílio com a palavra, seja a que es- capa de um texto, seja a que aparece em um livro, um mapa, no relato de uma recordação de viagem. Palavra que fala sempre da urgência de pertencimento, seja a uma casa ou ao mundo.

Em comum a essas experiências aparentemente distintas, o fato de que todo exilado deseja estar em um lugar onde não se encontra. E, por isso, o exilado inventa para si o que precisa onde quer que esteja - seja a casa fora de casa ou o mundo fora do mundo. Toda casa se torna mapa de mundo medido em pequenas distâncias, todo mundo se torna canto de casa apoiado em distâncias infinitas. Percorrer esses caminhos é a aventura que revela que casa e mundo são sempre carregados conosco e que, portanto, nem a casa e nem o mundo podem, no fim, ser-nos retirados. 
1 Parte deste texto é composto por escritos extraídos, com alterações, dos capítulos Casa-exílio e Morada-murmúrio, originalmente escritos para a tese de doutorado, em artes visuais, intitulada Palavra-livro, casa-exílio [por uma língua mal-dita] de Luciana Ferreira, sob orientação de Karina Dias [Universidade de Brasília, 2017-2021]. O texto aqui apresentado foi enriquecido pelas reflexões sobre as obras citadas de Adrian Paci e de Paulo de Nazareth.

2 Adrian Paci, autor da obra, era ele mesmo imigrante, um albanês que foi para a Itália em 1992.

3 Sobre o tema, ver Conversa infinita - a palavra plural, p.8594.

4 A tese de uma língua mal-dita é apresentada em Palavra-livro, casa-exílio [por uma língua mal-dita] onde, entre outras coisas, pode-se ler: "Mal-dita é a língua maldita em sentido ordinário, amaldiçoada por não se adaptar às regras e às expectativas. Assim é, também e por isso mesmo, a língua que é dita mal, uma língua livre em buscar caminhos, que deve pouco às normas e às instituições que a regulam. Uma língua que implode os limites que garantem a boa comunicação."[2021, p. 54]. Programa de Pós-Graduação em Artes Visuais - PPGAV- Universidade de Brasília.

5 Iniciado no ano de 2020, em plena pandemia, Todos os dias é um trabalho em processo de Karina Dias. $\bigcirc$ trecho onde poderia cair sem desastre é de autoria do poeta Paul Valet.
6 Em referência à epidemia do Coronavírus que confinou populações inteira ao redor do mundo. A epidemia começou no inicio de 2020 e perdura pelo ano de 2021

7 Em sua dissertação de mestrado, em fase final, intitulada Terra caídas, como navegar em águas rasas - sob orientação de Karina Dias [UnB], a artista Raíssa Studart vem desenvolvendo a compreensão de sua casa como um farol.

8 Título do artigo inédito do Grupo de pesquisa Vaga-mundo: poéticas nômades [CNPq]. Coordenação Profa. Dra. Karina Dias.

9 Em referência à Perec que escreve : [...] l'espace est un doute il me faut sans cesse le marquer, le designer ; il n 'ést jamais à moi [...] in PEREC, Georges. Espèces d'espaces. Paris: Galillée, 2000, p. 179. O espaço é uma dúvida: eu preciso constantemente marca-lo, designá-lo; ele nunca é meu. [tradução das autoras].

10 Vídeo inédito de autoria de Karina Dias e Albert Amabelakiotis realizado ao longo de 2020. Realizado a partir do reencontro com um mapa da américa do sul utilizado durante uma viagem por esse continente- realizada de 1995 a 1996 - e dos diários de bordo do período que compreendeu o trajeto. 
BACHELARD, Gaston. A poética do espaço. São Paulo: Marins Fontes, 2008.

BACHMANN, Ingeborg. O tempo adiado e outros poemas. São Paulo: Todavia, 2020

BLANCHOT, Maurice. A conversa infinita - a palavra plural. São Paulo: Escuta, 2010a.

BLANCHOT, Maurice. A conversa infinita - a experiência limite. São Paulo: Escuta, 2007.

BLANCHOT, Maurice. A conversa infinita - ausência do livro. São Paulo: Escuta, 2010b.

CAMUS, Albert. Diários de viagem. O verão. 1939-1953. http://revistapandorabrasil.com/camus/caumus_ do_mar_bem_perto.htm Consultado em 27/2/2021.

CORAJOUD, Michel. Le paysage c'est l'endroit où le ciel et la terre se touchent in ROGER, Alain [org.] La théorie du paysage en France, 1974-1994. Seyssel: Champ Vallon, 1995.

DARDEL, Eric. O homem e a terra. São Paulo: Perspectiva, 2011.

DERRIDA. Jacques \& DUFOURMANTELLE, Anne. Da Hospitalidade. São Paulo: Escuta, $\mid 2003$.

DELEUZE, Gilles, PARNET, Claire. Dialogues. Paris: Flammarion, 1996. 
DIAS, Karina. Entre visão e invisão: paisagem [por uma experiência da paisagem no cotidiano]. Brasília: Editora do Programa de Pós-graduação em Arte, Universidade de Brasília, 2010.

GALIENNE, Alicia. L'autre moitié du songe m’appartient poèmes. Paris: Gallimard, 2020.

JABÈS, Edmond. A obscura palavra do deserto [uma antologia]. Lisboa: Cotovia, 1991

LEVINAS, Emmanuel. De l'existence à l'existant. Paris: Vrin, 1993.

MARQUES, Ana Martins \& JORGE, Eduardo. como se fosse a casa [uma correspondência]. Belo Horizonte: Relicário edições, 2017

MARQUES, Ana Martins. O livro das semelhanças. São Paulo: Companhia das Letras, 2009.

MALDONADO, Mauro. O estrangeiro. In: Raízes errantes. São Paulo: Ed.34, 2004.

MERCATOR. Atlas. Amsterdam, 1609.

NAZARETH.Paulo. Arte contemporânea/LTDA. Rio de Janeiro: Cobogó, 2012.

WHITE, Kenneth. Le plateau d'albatros, introduction à la géopoétique. Paris: Grasset, 1994.

WHITE, Kenneth. Le poète cosmographe. Bordeaux: Presses Universitaires de Bordeaux, 1987. 